\title{
Influencing the Psychosocial Well-being of Nurses during the COVID-19
}

\author{
Shinyoung Park ${ }^{1}$, Min Jeong Chae ${ }^{2}$, Heesook Shin ${ }^{3}$ \\ ${ }^{1}$ Associate Professor, College of Chosun Nursing, Gwangju, Korea, cylove39@naver.com \\ ${ }^{2}$ Associate Professor, College of Chosun Nursing, Gwangju, Korea, minjung0960@ hanmail.net \\ ${ }^{3}$ Nursing Education Team Leader, Chosun University Hospital, Gwangju, Korea, \\ csh1986023@csuh.co.kr \\ Corresponding author: MinJeong Chae
}

\begin{abstract}
This study was conducted on nurses who are working in a tertiary hospital and general hospitals to identify their knowledge, resilience, and psychosocial well-being level of COVID-19. It is intended to provide basic data for improving the quality of nursing offered to infectious disease patients and performing efficient nursing tasks for them. The data was collected by filling out a structured self-report questionnaire targeting 202 nurses at the $\mathrm{C}$ tertiary hospital and the $\mathrm{S}$ general hospital. For data analysis, T-test, ANOVA, Pearson's correlation coefficient, and multiple regression were used utilizing SPSS 25.0 program. As a result of the study, the average level of knowledge about the Covid- 19 was $0.69 \pm 0.08$ points, the average resilience was $3.56 \pm 2.43$ points, and the psychosocial well-being was $1.26 \pm 0.44$ points. As a result of multiple regression analysis, it was confirmed that knowledge of COVID-19 $(\beta=-.31)$ and resilience $(\beta=-.63)$ had a significant effect on the psychosocial well-being of nurses $(\mathrm{F}=27.65, \mathrm{p}<.001)$, the explanatory power of the model was $21.7 \%$. Based on this study's results, it is necessary to develop and apply a program to improve resilience that affects practical competency targeting nurses who need to adapt to various clinical environments.
\end{abstract}

Keywords: COVID-19, Nurses, Psychosocial Well-being, Resilience

\section{Introduction}

The Coronavirus infectious disease-19 (COVID-19) outbreak in Wuhan, China in 2019, plunged Korea and the world into anxiety and fear[1], and social structural changes and economic downturn are experienced due to new diseases that have not been suffered before[2]. COVID-19 is a respiratory syndrome caused by SARS-CoV-2 infection. It is spread through droplets generated when coughing or sneezing and droplets or contact with eyes, nose, mouth, etc., after touching objects contaminated with the novel corona virus[3]. In general, it is characterized by high fever. Still, in severe cases of chills, cough, difficulty breathing, muscle pain, headache, fatigue, loss of taste or smell, and pneumonia, fatal symptoms such as blood coagulation, heart attack, stroke, and multiple encephalitides appear[4]. In a paper that analyzed 5464 people worldwide, the mortality rate was $21 \%$ [5].

The spread of COVID-19 is a target of fear not only to medical staff such as doctors and nurses who directly contact and treat patients, but also to the general public. It also affects depression and anxiety psychologically and socially[6]. In particular, with the continuous increase of confirmed cases, safety text messages through broadcasting media have become daily life, and the closure of visited areas,

Received: November 24, 2020; $1^{\text {st }}$ Review Result: January 13, 2021; $2^{\text {nd }}$ Review Result: February 28, 2021 Accepted: March 29, 2021 
regulations on the use of multiple facilities, refrain from visiting restaurants or public places, hand sanitization, and the use of masks are making many changes in our society[7]. On February 23, 2020, concerning the spread of the new infectious disease COVID-19, the government upgraded the national infectious disease crisis response stage to the highest level of 'severe'. It reinforced the active response system[8], and Mike Ryan, Deputy Secretary-General of WHO Emergency Preparedness Response Said that corona could go beyond a global pandemic, to become an endemic phenomenon, which means a virus that kills people every year[9].

Infectious diseases are legal disasters specified in the fundamental law on disaster and safety management. Unlike disasters in which step-by-step activities are carried out according to the disaster development pattern, it requires a preventive strategy to stop the spread of the disease continuously at the same time as response and recovery[10]. In particular, since infectious diseases are medical disasters[11], there is high uncertainty regarding disasters. Social anxiety and fear may be amplified due to the low predictability of transmission[10]. Thus, an active action from health care providers is required as a disaster response strategy. Nurses, which account for the largest proportion of the health care Workforce, have a wide range of risk of exposure to infection because they contact suspected patients, confirmed patients, and quarantine subjects while caring for patients such as sample collection, fluid therapy, and aspiration[12].

While experiencing the spread of a new pandemic, one may fall into a pathological condition and exhaust, or escape from shock and recover or grow[13]. In many studies, the case of enduring adversity in the face of an environmental crisis and going to a positive recovery mode is regarded as resilience, and continuous research is being conducted[14]. In nurses' case, resilience acts as a critical important variable in performing work[11] and affects psychosocial well-being levels, and the degree of resilience may respond differently according to individual differences[1].

As a related foreign prior research, there is a study to understand the impact of Coronavirus on mental health, well-being, and dignity of the general public and to confirm the psychological effects and psychosocial results of resilience related to the COVID-19 pandemic[15] and a study to confirm the psychological problems of medical professionals who manage corona patients in institutional isolation during the COVID-19 pandemic[16] and a study to verify support organizations, stress, the duty of care, and anxiety among 462 nurses working in acute treatment hospitals during the COVID19 pandemic[17]. As a related domestic prior research, there is a study to confirm the level of resilience and psychosocial well-being to COVID-19 in nurses[11], a study of differences in selfresilience, depression, and psychological emotions in COVID-19 situations in first-year college students[7] and a study to verify the effects of fear of COVID-19 infection and psychosocial experiences on depression and anxiety in the general public[18]. Looking at the prior research, studies on nurses related to COVID-19 are insufficient.

Therefore, since nurses are in close contact with patients related to COVID-19, this study is intended to provide basic data to confirm the knowledge, resilience, and psychosocial well-being level of nurses and to improve the quality of care provided to infectious disease patients and to carry out efficient nursing services to patients with infectious diseases. Specific research questions are as follows.

First, are the subject's knowledge of COVID-19, resilience, and psychosocial well-being related to each other?

Second, What is the factors that affect the subject's psychosocial well-being?

\section{Method}

\subsection{Study Design}


This descriptive research uses a self-report questionnaire on nurses, to identify their knowledge, resilience, and psychosocial well-being level of COVID-19, and to provide basic data for the improving the quality of nursing offered to infectious disease patients and performing efficient nursing tasks for them.

\subsection{Samples}

The subjects of this study were determined using convenience sampling from the nurses of the $\mathrm{C}$ tertiary hospital and S general hospital located in $\mathrm{G}$ city, and the data collection was conducted from October 26, 2020 to November 06, 2020. Before receiving consent to participate in the study, they were explained that their data are used only for research purposes, and that they are strictly confidential, and that if they do not want to participate in the response, they can stop at any time. Using the $G^{*}$ Power 3.1.9 program for the number of samples, when including the two-sided test significance level $\alpha=.05$, effect size $=.15$, predictor variable for multiple regression, the minimum number of samples to maintain the power of .95 were 172 people. A total of 210 questionnaires were distributed in consideration of the dropout rate. Among them, 208 questionnaires were collected, but the final study was conducted on 202 copies, excluding 6 questions that did not respond faithfully.

\subsection{Instrument}

\subsubsection{Covid-19 Knowledge}

As a tool for knowledge of COVID-19, 23 questions developed by Yoon (2020)[11] were used. As for the degree of knowledge about COVID-19, when the correct answer is scored as 1 and the incorrect answer is scored as 0 , the lowest score is 0 and the highest score is 23 . This means the higher the total score, the higher the knowledge about COVID-19. At the time of development, the item reliability of Kuder-Richardson $20(\mathrm{KR} 20)=.15$, and the item reliability KR-21 of this study was .18 .

\subsubsection{Resilience}

Resilience is the ability to adapt to changing circumstances and crisis situations, and Baek et al. (2010)'s[19] Korean resilience tool (K-CD-RISC) was used. The tool is toughness, persistence, optimism, support, and spirituality, with a total of 25 questions. Each question is measured on a 5point scale, and the higher the score, the higher the degree of resilience. The reliability of the tool was .93 in Baek et al. (2010)[19] and .90 in this study.

\subsubsection{Psycosocial Well-bing}

The psychosocial well-being measurement tool was developed by Jang (2000)[20] according to the situation in Korea, and the shortened PWI-SF was used to verify the validity and reliability of 18 items. The tool is 0 to 3 points, and when a 4-point scale is applied, the higher the score, the higher the psychosocial stress. 27 points or more are 'high risk group', 9 to 26 points are 'potential stress group', 8 points Below are classified as 'healthy group'. The reliability of the tool was Cronbach's $\alpha=.90$ in the study of Jang (2000)[20], and .89 in this study.

\subsection{Data Analysis}

The data were analyzed using SPSS WIN/PC 25.0 in order to understand the factors that influence the psychosocial well-being of nurses with the collected data.

1) The general characteristics of the subjects were calculated as mistakes and percentages. The 
knowledge, resilience, and psycholsocial well-being of the subjects were calculated as mean and standard deviation.

2) Independent t-test and ANOVA were used for knowledge, resilience, and psychosocial well-being according to the general characteristics of the subjects, and the post-test was analyzed by the Scheffé test.

3) The relationship between the subject's knowledge, resilience, and psychosocial well-being was analyzed using Pearson's correlation coefficient.

4) Multiple regression analysis was used to analyze the factors affecting the subject's psychosocial well-being.

\section{Results}

\subsection{General Characteristics of the Participants}

The results of frequency analysis to understand the general characteristics of the study subjects are as follows [Table 1]. As for the type of hospital, tertiary hospitals (176 participants, $87.1 \%$ ) were more frequent than general hospitals (26 participants, 12.9\%), females (196 participants, 97.0\%) were the majority, and educational level was higher in bachelor's (169 participants, 83.7\%) than master's (33 participants, 16.3\%). There were more cases with religion (130 participants, 64.4\%) than those without religion (72 participants, 35.6\%). As for the work experience, more than 6 months-less than 36 months(63 participants, 31.2\%), more than 120 months-less than 240 months(41 participants, 20.3\%), more than 60 months-less than 120 months(38 participants, 18.8\%), more than 36 months-less than 60 months(34 participants, $16.8 \%$ ), more than 240 months(26 participants, $12.9 \%$ ) is many in this order.

\subsection{Covid-19 Knowledge, Resilience and Psycosocial Well-bing Level}

Degree of knowledge about COVID-19 was a total of 23 questions, and when the correct answer was 1 and the incorrect answer was 0 , each question showed an average of $0.69 \pm 0.08$ points out of 1 point. Resilience was measured on a 5-point scale ranging from 0 to 4 with a total of 25 questions, and was averaged $3.56 \pm 2.43$ points out of 4 points. When examining the scores for each sub-factor, supportability was $3.01 \pm 0.62$ points, persistence was $2.60 \pm 0.56$ points, optimism was $2.35 \pm 0.63$ points, toughness was $2.24 \pm 0.56$ points, and spirituality was $2.20 \pm 0.64$ points. Psychosocial wellbeing was measured with a total of 18 questions ranging from 0 to 3 points, and inverse conversion was performed for 8 inverse questions, and the overall average score was $1.26 \pm 0.44$. The level of psychosocial well-being can be classified into a health group (0-8 points), a potential stress group (926 points), and a high-risk stress group ( 27 points or more) based on a total score of 54 points. As a result of the frequency analysis, it was found in the healthy group $(2.5 \%)$, the potential stress group $(64.9 \%)$, and the high-risk stress group (32.7\%) [Table 2].

[Table 1] General Characteristics of the Participants $(\mathrm{N}=202)$

\begin{tabular}{|c|c|c|}
\hline Characteristics & Categories & $\mathbf{n ( \% )}$ \\
\hline \multirow{2}{*}{ Hospital type } & tertiary hospital & $176(87.1)$ \\
\cline { 2 - 3 } & general hospital & $26(12.9)$ \\
\hline \multirow{2}{*}{ Gender } & male & $6(3.0)$ \\
\cline { 2 - 3 } & female & $196(97.0)$ \\
\hline
\end{tabular}




\begin{tabular}{|c|c|c|}
\multirow{4}{*}{ Graduate degree } & bachelor & $169(83.7)$ \\
\cline { 2 - 3 } & master & $33(16.3)$ \\
\hline \multirow{3}{*}{ Religion } & yes & $130(64.4)$ \\
\cline { 2 - 3 } & no & $72(35.6)$ \\
\hline \multirow{3}{*}{ Clinical career(month) } & $6-36$ & $63(31.2)$ \\
\cline { 2 - 3 } & $37-60$ & $34(16.8)$ \\
\cline { 2 - 3 } & $61-120$ & $38(18.8)$ \\
\cline { 2 - 3 } & $121-240$ & $41(20.3)$ \\
\cline { 2 - 3 } & $240<$ & $26(12.9)$ \\
\hline
\end{tabular}

[Table 2] Covid-19 Knowledge, Resilience and Psycosocial Well-bing Level (N=202)

\begin{tabular}{|c|c|c|c|}
\hline Variables & $\mathbf{N}(\%)$ & $\mathbf{M} \pm$ SD & Range \\
\hline Covid-19 knowledge & & $0.69 \pm 0.08$ & $1.44-3.56$ \\
\hline Resilience & & $3.56 \pm 2.43$ & $1.11-3.78$ \\
\hline Hardiness & & $2.24 \pm 0.56$ & $1.38-4.00$ \\
\hline Persistence & & $2.35 \pm 0.63$ & $1.00-4.00$ \\
\hline Optimism & & $3.01 \pm 0.62$ & $.00-4.00$ \\
\hline Supportability & & $2.20 \pm 0.64$ & $.22-2.39$ \\
\hline Spirituality & & $1.26 \pm 0.44$ & \\
\hline Psycosocial well-bing & & & \\
\hline Healthy & $5(2.5)$ & & \\
\hline Potential stress & $131(64.9)$ & & \\
\hline Severe stress & $66(32.7)$ & & \\
\hline
\end{tabular}

\subsection{Difference of Variables according to Sociodemographic Characteristics of Participants}

Resilience according to demographic characteristics showed a significant difference in accordance with religion $(\mathrm{t}=-2.74, \mathrm{p}=.007)$. The case of no religion showed relatively higher resilience than the case of religion.

There were significant differences in psychosocial well-being according to hospital type $(\mathrm{t}=2.23$, $\mathrm{p}=.035)$ and education level $(\mathrm{t}=-2.46, \mathrm{p}=.015)$. Nurses working in tertiary hospitals had higher psychosocial well-being levels than nurses working in general hospitals, and those with a master's degree or higher had higher psychosocial well-being levels than those with a bachelor's degree [Table $3]$. 
[Table 3] Difference of Variables according to Sociodemographic Characteristics of Participants ( $N=202)$

\begin{tabular}{|c|c|c|c|c|c|c|c|}
\hline \multirow{3}{*}{$\begin{array}{c}\text { Characteristics } \\
\text { Hospital }\end{array}$} & \multirow{3}{*}{$\begin{array}{c}\text { Categories } \\
\text { tertiary } \\
\text { hospital }\end{array}$} & \multirow{2}{*}{\multicolumn{2}{|c|}{$\begin{array}{c}\text { Covid-19 knowledge } \\
M \pm S D \text { t/F(p) }\end{array}$}} & \multirow{2}{*}{\multicolumn{2}{|c|}{$\begin{array}{c}\text { Resilience } \\
\mathbf{M} \pm \text { SD t/F(p) }\end{array}$}} & \multirow{2}{*}{\multicolumn{2}{|c|}{$\begin{array}{c}\text { Psychosocial well-bing } \\
\mathrm{M} \pm \text { SD t/F(p) }\end{array}$}} \\
\hline & & & & & & & \\
\hline & & $15.73 \pm 1.88$ & \multirow{2}{*}{$-1.42(.158)$} & $60.23 \pm 10.74$ & \multirow{2}{*}{$-1.87(.063)$} & $23.05 \pm 7.63$ & \multirow{2}{*}{$2.23(.035)$} \\
\hline type & $\begin{array}{l}\text { general } \\
\text { hospital }\end{array}$ & $16.27 \pm 1.31$ & & $65.54 \pm 12.54$ & & $19.58 \pm 8.68$ & \\
\hline \multirow{2}{*}{ Gender } & male & $1600 \pm 2.28$ & \multirow{2}{*}{$.28(.783)$} & $63.50 \pm 14.79$ & \multirow{2}{*}{$.61(.543)$} & $25.50 \pm 9.73$ & \multirow{2}{*}{$.92(.359)$} \\
\hline & female & $15.79 \pm 1.81$ & & $60.70 \pm 10.95$ & & $22.52 \pm 7.79$ & \\
\hline \multirow{2}{*}{ Education } & bachelor & $15.80 \pm 1.71$ & \multirow{2}{*}{$.03(.975)$} & $60.06 \pm 10.51$ & \multirow{2}{*}{$-1.85(.071)$} & $23.20 \pm 7.72$ & \multirow{2}{*}{$2.46(.015)$} \\
\hline & master & $15.79 \pm 2.37$ & & $64.52 \pm 13.01$ & & $19.58 \pm 7.85$ & \\
\hline \multirow{2}{*}{ Religion } & yes & $15.84 \pm 1.66$ & \multirow{2}{*}{$-.19(.851)$} & $59.52 \pm 10.55$ & \multirow{2}{*}{$-2.74(.007)$} & $22.57 \pm 7.81$ & \multirow{2}{*}{$.89(.370)$} \\
\hline & no & $15.89 \pm 2.27$ & & $64.54 \pm 11.77$ & & $21.40 \pm 7.68$ & \\
\hline \multirow{5}{*}{$\begin{array}{l}\text { Clinical } \\
\text { Career } \\
\text { (month) }\end{array}$} & $6-36$ & $15.32 \pm 1.63$ & \multirow{5}{*}{$2.01(.095)$} & $59.05 \pm 10.46$ & \multirow{5}{*}{ 1.87(.117) } & $24.75 \pm 6.94$ & \multirow{5}{*}{$2.38(.053)$} \\
\hline & $37-60$ & $15.82 \pm 2.05$ & & $62.91 \pm 10.52$ & & $21.15 \pm 7.22$ & \\
\hline & $61-120$ & $15.87 \pm 2.08$ & & $60.13 \pm 10.05$ & & $22.58 \pm 9.21$ & \\
\hline & $121-240$ & $16.10 \pm 1.83$ & & $59.59 \pm 12.45$ & & $22.32 \pm 8.17$ & \\
\hline & $240<$ & $16.35 \pm 1.38$ & & $65.08 \pm 11.39$ & & $22.60 \pm 7.84$ & \\
\hline
\end{tabular}

\subsection{Correlation between Covid-19 Knowledge, Resilience and Psychosocial Well-bing}

The results of Pearson's correlation analysis on the correlation between knowledge, resilience, and psychosocial well-being about COVID-19 are as follows [Table 4]. Knowledge and psychosocial wellbeing showed a significant negative correlation $(\mathrm{r}=-.166, \mathrm{p}=.018)$, and resilience and psychosocial well-being showed a significant negative correlation $(r=-.443, \mathrm{p}<.001)$.

[Table 4] Correlation between Covid-19 Knowledge, Resilience and Psychosocial Well-bing (N=202)

\begin{tabular}{|c|c|c|c|}
\hline \multirow{2}{*}{ Variables } & Covid-19 knowledge & Resilience & Psychosocial well-bing \\
\cline { 2 - 4 } & $\mathbf{r}(\mathbf{p})$ & $\mathbf{r}(\mathbf{p})$ & \\
\hline Covid-19 knowledge & 1 & & \\
\hline Resilience & $.044(.532)$ & 1 & 1 \\
\hline Psychosocial well-bing & $-.166(.018)^{*}$ & $-.443(<.001)^{* *}$ & \\
\hline
\end{tabular}

$* \mathrm{p}<.05, * * \mathrm{p}<.001$

\subsection{Factors Influencing the Level of Psychosocial Well-bing of Nurses}

The results of multiple regression analysis was [Table 5] to identify factors that affect the level of 
social and psychosocial well-being of nurses. As a result of confirming the multicollinearity of the entire variable, it was found that there was no multicollinearity because the variance inflation factor (VIF) was all less than 10 , and the Durbin-Watson result was 1.982, indicating that there was no autocorrelation. The assumptions of linearity, normality, and homoscedasticity to satisfy the assumption of residuals were also satisfied. The Cook' distancs value for examining the singular value did not exceed 1.0, so it was confirmed that there was no singular value. As a result of analyzing the regression model, it was found that the regression model was significant $(\mathrm{F}=27.65, \mathrm{p}<.001)$, and the modified coefficient of determination (R2) indicating the explanatory power of the model was .21. Resilience and knowledge were found to have a negative effect on the psychosocial well-being of nurses. In particular, the sub-factors of resilience were in the order of persistence $(\beta=-.438$, $\mathrm{p}=<.001)$, optimism $(\beta=-.386, \mathrm{p}=<.001)$, and hardiness $(\beta=-.364, \mathrm{p}=<.001)$, supportability $(\beta=-.249$, $\mathrm{p}=<.001)$, spirituality $(\beta=-.097, \mathrm{p}=<.001)$.

[Table 5] Factors Influencing the Level of Psychosocial Well-bing of Nurses $(\mathrm{N}=202)$

\begin{tabular}{|c|c|c|c|c|c|c|c|c|c|c|}
\hline \multicolumn{3}{|c|}{ Variables } & B & SE & $\beta$ & $\mathbf{t}$ & $\mathbf{p}$ & Adj.:R & $\mathbf{F}$ & $\mathbf{p}$ \\
\hline \multirow{7}{*}{$\begin{array}{l}\text { psychosocial } \\
\text { well-bing }\end{array}$} & \multicolumn{2}{|c|}{ Covid-19 knowledge } & -.31 & .27 & -.147 & 5.31 & .020 & \multirow{7}{*}{.217} & \multirow{7}{*}{27.65} & \multirow{7}{*}{$<.001$} \\
\hline & \multirow{6}{*}{ Resilience } & total & -63 & .05 & -.436 & -5.23 & $<.001$ & & & \\
\hline & & Hardiness & -5.1 & .92 & -.364 & -5.53 & $<.001$ & & & \\
\hline & & Persistence & -7.2 & 1.05 & -.438 & -6.89 & $<.001$ & & & \\
\hline & & Optimism & -4.82 & .82 & -.386 & -5.92 & $<.001$ & & & \\
\hline & & Supportability & -3.14 & -86 & -.249 & -3.64 & $<.001$ & & & \\
\hline & & Spirituality & -1.19 & .86 & -.097 & -1.39 & $<.001$ & & & \\
\hline
\end{tabular}

\section{Discussion}

This study attempted to provide basic data to confirm the effect of nurses' knowledge and resilience of COVID-19 on the psychosocial well-being level, and to establish nursing strategies for responding to infectious diseases of nurses who account for the largest proportion of members of tertiary hospitals and general hospitals.

The rate of the correct answer to knowledge about COVID-19 by nurses was $69 \%$. This was $72 \%$ in a study[11] of nurses using the same tools. When compared for each question, the rate of correct answers related to COVID-19 symptoms was $100 \%$. The correct answers related to quarantine release were $23 \%$, which was similar to $99 \%$ and $24 \%$ in the results of this study. Also, the knowledge about infection control appeared $74.5 \%$ in a study on Ebola virus infection control for nurses[21], and 67.3\% in a study on new respiratory infectious diseases[22], and 69\% in a study on MERS infection control[23]. There were not many previous studies using the same measurement tool and question, so it was difficult to compare with this result. Among the knowledge questions in this study, the rate of correct answers was high for COVID-19 symptoms, specimen collection, prevention guidelines for 
patient management, and preventive Vaccines, while the rate of correct answers was low in the release of quarantine, criteria for confirmed patients, upper respiratory tract specimens, and management of subjects for self-isolation. This means, although nurses know the overall intervention strategies and provide nursing care because the state of outbreaks and prevention rules are continuously publicized at the national level in the event of an infectious disease epidemic[11], more education about the specialized and specific knowledge on the new respiratory infectious diseases[22] should be done.

The nurse's resilience was averaged 3.56 out of 4 points. When checking each sub-factor scores, support was 3.01 points, persistence was 2.60 points, optimism was 2.35 points, toughness was 2.24 points, and spirituality was 2.20 points. These results were higher than 2.48 points[11], 2.45 points[24], and 2.5 points[25], which are the results of studies using the same measuring tool. Unlike previous studies targeting nurses working in emergency rooms or trauma centers, this study targets nurses working in various departments such as general ward, intensive care unit, emergency room, outpatient, and infection control room. It seems that circumstances and personal characteristics have influenced the research results. In terms of resilience according to the subjects' general characteristics, there was a significant difference in religion, which was similar to the results of a study[24] of a trauma center nurse. It was found that supportability was the highest in the sub-factors. These results show that others' support of others has a lot of influence[25] in overcoming stressful environments and negative situations. It emphasizes the importance of peer support[11] in training for disaster response, such as COVID-19. In particular, because resilience has flexibility according to the adaptation of the working environment[26], it is judged that a strategy to establish a support system for the hospital organization and increase resilience is necessary for nurses to adapt well to the environment.

The overall average score for psychosocial well-being was 1.26 points. The level of psychosocial well-being was found in the healthy group (2.5\%), the potential stress group (64.9\%), and the highrisk stress group (32.7\%). These results were similar to those classified based on the overall average score and individual scores compared with the results of a study on nurses[11]. Psychosocial wellbeing refers to psychological stress in occupational work, and is influenced by the degree of exposure to psychosocial risk among occupational characteristics[27]. Factors that affect medical workers' mental health in an infectious disease include stress, exposure risk, and support systems. Since stress has a large effect on mental health[28], various Intervention strategies to reduce stress must be sought. When looking at the psychosocial well-being level according to the subjects' general characteristics, there was a significant difference in the type of hospital and the level of education, which was similar to the results of a study showing a significant difference in the level of education [11]. In particular, it is believed that there will be a difference because a tertiary hospital has a systematic infection control and prevention system to prepare effectively and respond to the risk of infectious diseases and is equipped with negative pressure facilities, infection specialists, and specialized equipment than a general hospital. Also, it is difficult to generalize in the case of education level, so further repetitive studies are needed.

In this study, as a result of analyzing the correlation between the knowledge about COVID-19, resilience, and psychosocial well-being level, resilience and psychosocial well-being showed a significant negative correlation $(\mathrm{p}<.001)$. This is similar to the study results targeting nurses[11] and hospital workers and the general public[1]. Still, it is difficult because there are no comparative prior studies that can support this study. As a result of previous studies, resilience plays a role as a mediator or buffer. The degree of stress of individuals suffering from the MERS outbreak affects psychosocial well-being[1], and the higher the resilience, the better the psychosocial well-being[7]. Multiple regression analyses to identify factors influencing psychosocial well-being level, knowledge and resilience related to COVID-19 were statistically significant, and showed $22 \%$ explanatory power. Particularly, as the sub-factors of resilience, it was confirmed that persistence, optimism, hardiness, supportability, and spirituality affect the psychosocial well-being level in order. Therefore, there is a 
desperate need for administrative and financial support necessary to find ways to overcome the stress experienced by nurses and increase their resilience, and to improve their adaptation and performance in clinical situations. In addition, it is necessary to continuously develop a mental health program for nurses caring for infectious diseases and to confirm its effectiveness.

\section{Conclusions and Recommendations}

This study was conducted to identify the level of knowledge, resilience and psychosocial well-being level related to COVID-19, and confirm the relationship among nurses. As a result of the study, in terms of nursing research, nurses' knowledge and resilience about the new infectious disease had a significant effect on the psychosocial well-being level. In the case of resilience, which is the most important influencing factor, its sub-area was persistence, optimism, hardiness, supportability, and spirituality in the order. In the case of knowledge, there was a difference for each item. When the clinical symptoms and test criteria, quarantine release criteria and conditions, meaning of active surveillance, contact criteria with family members and domestic partners of self-isolation, and test collection criteria of COVID-19 confirmed patients are based on the maximum value of 1 , the score was below .05. As the score was shown, it is necessary to develop various infection control education programs to improve nurses' knowledge level.

Also, it was possible to confirm based on the results of the sub-area of resilience, that clear selfconfidence, persistence that means careful decision-making when stressed and tolerance to negative influences, positive acceptance of change and optimism of adaptation, individual competence, high standards, hardiness not to be easily frustrated when faced with adversity, supportability relationships with social supporters, family members, friends, etc. Spirituality of faith in God is related to psychosocial well-being level. In particular, persistence can influence nurses who directly care for patients in national disasters such as COVID-19. spirituality in this study showed a significant difference between the presence and absence of religion. The interpretation of these results differs depending on the diversity of religions, so it seems necessary to reconfirm through further research.

Unlike previous studies, in which only correlations between variables were confirmed using the same tool as in this study based on the results of the study, this study analyzed not an only correlation with the knowledge about COVID-19, resilience, and psychosocial well-being level, but also Influencing factors according to the sub-area as variables of resilience that positively affects the improvement of nursing quality and individual competence for nurses who need to adapt to various clinical environments. Furthermore, it is intended to provide basic data to improve job satisfaction. Therefore, it is thought that it can be used as basic data to improve nurses' effective work commitment and job satisfaction in the continuously changing medical environment. Through the results of the study, additional studies for nurses in various regions are required, and in future studies, more studies with various variables are suggested.

\section{References}

[1] H. M. Kwon, T. H. Kim, M. R. Choi, B. J. Kim, H. W. Kim, O. S. Song, H. J. Eun, The Effects of MERS(Middle East Respiratory Syndrome) Event on the Psychosocial Wellbeing of Healthcare Workers and the Public with the Mediating Effect of Resilience, Korean Journal of Psychosomatic Medicine, (2017), Vol.25, No.2, pp.111-119, https://doi.org/10.22722/KJPM.2017.25.2.111

[2] M. J. Chung, Infectious Disease, Safety, State: History of Infectious Disease Prevention and MERS Situation, Critical Studies on Modern Korean History, (2015), Vol.34, No.2, pp.517-542.

[3] http://ncov.mohw.go.kr/baroView.do?brdId=4\&brdGubun=41, Apr 2 (2021) 
[4] B. P. M. Iser, I. Sliva, V. T. Raymundo, M. B. Poleto, F. Schuelter-Trevisol and F. Bobinski, Suspected COVID-19 case definition: a narrative review of the most frequent signs and symptoms among confirmed cases, Epidemiol Serv Saude, (2020), Vol.29, No.3, pp.1-11.

[5] https://www.medigatenews.com/news/1264676912, Apr 17 (2020)

[6] D. H. Lee, Y. J. Kim, D. H. Lee, H. H. Hwang, S. K. Nam, J. Y. Kim, The Influence of Public Fear, and Psycho-social Experiences during the Coronavirus Disease 2019 (COVID-19) Pandemic on Depression and Anxiety in South Korea, Korean Journal Of Counseling And Psychotherapy, (2020), Vol.32, No.4, pp.2119-2156, DOI : 10.23844/kjcp.2020.11.32.4.2119

[7] H. J. Yang, Differences in Depression and Psychological Emotions According to the Degree of Self-elasticity of College Freshmen in COVID-19, The Journal of the Convergence on Culture Technology, (2020), Vol.6, No.3, pp.7582 .

[8] COVID-19 response guidelines (edition 6), Korea Centers for Disease Control and Prevention, (2020a)

[9] https://www.donga.com/news/Inter/article/all/20200514/101035897/1, May 14 (2020)

[10] https://www.kipa.re.kr/site/kipa/research/selectPublishView.do?gubun=IS\&pblcteId=PUBL_000000000000483, Feb $20(2020)$

[11] S. R. Yun, Correlations between Nurses' Knowledge of COVID-19 and infection Control Compliance, Resilience, and Psychosocial Well-being, Chung-Ang University, Master's Thesis, (2020)

[12] H. S. Kang, Y. D. Son, S. M. Chae, C. Corte, Working experiences of nurses during the Middle East respiratory syndrome outbreak, International Journal of Nursing Practice, (2018), Vol.24, No.5, pp.1-8, https://doi.org/10.1111/ijn.12664

[13] J. M. Schneider, Finding My Way: Healing and Transformation Through Loss and Grief, Seasons Press, (1994)

[14] K. M. Connor, Assessment of Resilience in the Aftermath of Trauma, Journal of Clinical Psychiatry, (2006), Vol.67, No.2, pp.46-49.

[15] G. Ivbijaro, C. Brooks, L. Kolkiewicz, C. Sunkel, A. Long, Psychological impact and psychosocial consequences of the COVID 19 pandemic Resilience, mental well-being, and the coronavirus pandemic, Indian Journal of Psychiatry, (2020), Vol.62, No.9, pp.395-403.

[16] P. Rathore, S. Kumar, N. Choudhary, R. Sarma, N. Singh, N. Haokip, S. Bhopale, A. Pandit, B. K. Ratre and S. Bhatnagar, Concerns of Health-care Professionals Managing COVID Patients under Institutional Isolation during COVID-19 Pandemic in India: A Descriptive Cross-sectional Study, Indian Journal of Palliative Care, (2020), Vol.26, No.5, pp.90-94.

[17] L. Cathaleen, J. Barbara, Perceptions of Nurses Staff During the COVID-19 Pandemic, Maryland Nurses Association, (2020), Vol.21, No.5, p.7.

[18] COVID-19 response guidelines (edition 7-3), Korea Centers for Disease Control and Prevention, (2020)

[19] H. S. Baek, K. U. Lee, E. J. Joo, M. Y. Lee, K. S. Choi, Reliability and Validity of the Korean Version of the ConnorDavidson Resilience Scale, Psychiatry investigation, (2010), Vol.7, No.2, pp.109-115.

[20] S. J. Jang, Standardization of health statistics collection and measurement, Gyechuk Munwhasa, (2000)

[21] J. H. Han, The relationship between Knowledge, Awareness, and Health Beliefs in Nurses' Ebola Virus Infection Control, Chungbuk National University, Master's Thesis, (2020)

[22] Y. E. Choi, E. S. Lee, A Study on Knowledge, Attitude, Infection Management Intention \& Educational needs of New Respiratory Infectious Disease among Nurses who unexperienced NRID(SARS \& MERS), Journal of the Korea Academia-Industrial Cooperation Society, (2019), Vol.20, No.2, pp.721-731, DOI:10.5762/KAIS.2019.20.2.721

[23] Y. J. Ji, Nurses` knowledge, Educational Needs, and Practice Regarding MERS Infection Control, Woosuk University, Master's Thesis, (2018)

[24] H. Y. Youn, Influencing Factors of Stress Coping Strategies, Resilience on Post-traumatic Growth of Nurses in 
Regional Trauma Centers, Korea National University of Transportation, Master's Thesis, (2020)

[25] J. M. Jeong, M. H. Sung, Impact of Role Conflict, Self-efficacy, and Resilience on Nursing Task Performance of Emergency, Korean Journal of Occupational Health Nursing, (2018), Vol.27, No.1, pp.59-66.

[26] E. J. Jeong, Influence of small and medium-sized hospital nurse with violence experiences, social support and resilience on nurse job performance, Nambu University, Master's Thesis, (2017)

[27] J. Y. Lee, M. J. Lee, S. Y. Park, The Impact of Psychosocial Health and Self-nurturance on Graduate Nurse Experience, Journal of Korean Academy of Nursing Administration, (2015), Vol.21, No.5, pp.459-468, https://doi.org/10.11111/jkana.2015.21.5.459

[28] J. S. Park, The Effect of Precarious Employment on the Mental Health, Seoul National University, Master's Thesis, (2016) 